

\begin{tabular}{l|l|l|l|l|l}
\hline Table 1. Advantages and disadvantages of bonded retainers \\
\hline Advantages & Disadvantages \\
\hline $\begin{array}{l}\text { When compared with removable } \\
\text { retainers: }\end{array}$ & $\begin{array}{l}\text { More complicated oral } \\
\text { hygiene procedures }\end{array}$ \\
\hline Requires little patient compliance & Possible obstruction of the occlusion \\
\hline Superior aesthetics & $\begin{array}{l}\text { Impassive wire can result in unwanted } \\
\text { tooth movement }\end{array}$ \\
\hline More predictable long-term retention & \\
\hline \begin{tabular}{l} 
Specific to multi-stranded wire retainers: \\
\hline $\begin{array}{l}\text { Flexibility of the wire allows for } \\
\text { physiological tooth movement }\end{array}$
\end{tabular} \\
\hline $\begin{array}{l}\text { Irregular surface should give increased } \\
\text { mechanical retention for the composite }\end{array}$
\end{tabular}

A retention period of 12 months is commonly recommended because of this ${ }^{10}$ but relapse can still occur after this time because of skeletal growth and maturation of the soft tissue, so indefinite retention has been advocated to minimise this. ${ }^{11,12}$ Long term retention is commonly achieved with fixed retainers, especially for the lower anterior teeth..$^{13,14}$ have since been proposed but the multistranded wire, introduced by Björn Zachrisson, ${ }^{17,18}$ is now the gold standard. ${ }^{13}$ Multi-stranded wire is round or rectangular in cross-section and formed from strands that are twisted (Fig. 1), arranged coaxially (five wires of equal size wrapped around a single, core of wire of the same-size) (Fig. 2) or

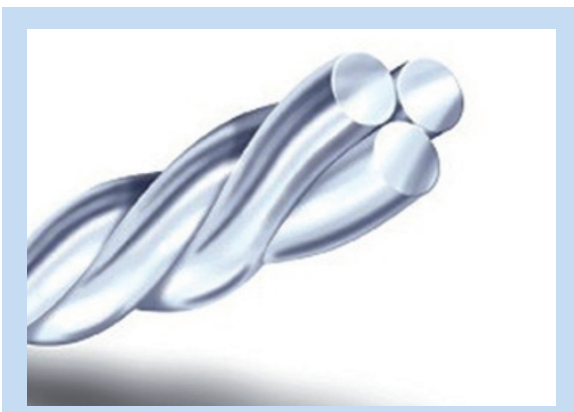

Fig. 1 Three stranded twisted round wire

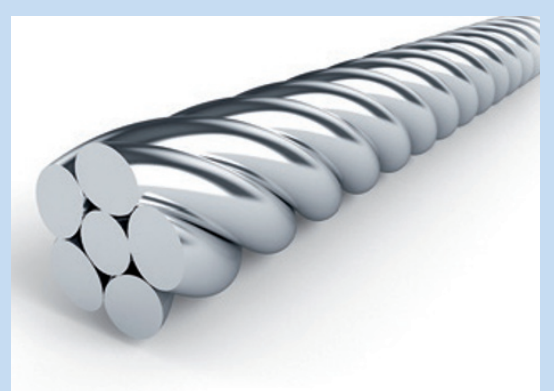

Fig. 2 Six stranded coaxial round wire

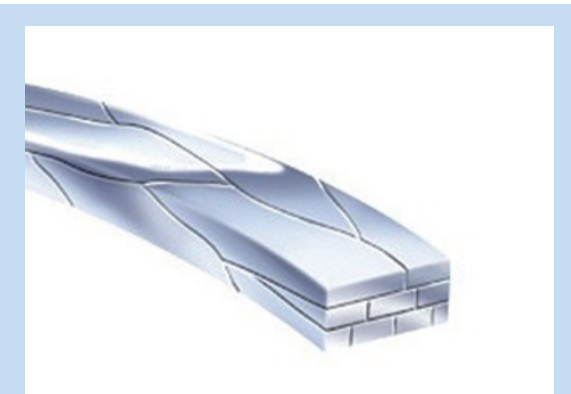

Fig. 3 Eight stranded braided rectangular wire

predictable long-term retention compared with removable retainers. ${ }^{13}$

Multi-stranded wire has been a successful material for bonded retainers because its flexibility allows for physiological tooth movement, ${ }^{22}$ meaning that teeth can move independently of one another, making bond failure less likely. ${ }^{13,21}$ The irregular surface of this material means that it has a greater surface area than regular wire, which should give increased mechanical retention for the composite. ${ }^{18}$

It is generally accepted that bonded retainers complicate oral hygiene procedures ${ }^{23}$ but while the presence of a bonded retainer has been associated with an increased incidence of gingival recession, increased plaque accumulation and increased bleeding on probing, ${ }^{24}$ it does not necessarily lead to caries, ${ }^{23,24}$ affect periodontal health ${ }^{22,25}$ or lead to long-term tissue damage. ${ }^{26,27}$

As with all bonded retainers, care needs to braided (Fig. 3). ${ }^{13,19-21}$ Multi-stranded wire for most commonly round in crossavailable in imperial ( 0.015 " to 0.0215 ") and metric $(0.38 \mathrm{~mm}$ to $0.5 \mathrm{~mm})$ sizes from various orthodontic supply companies. Gold $(0.5 \mathrm{~mm})$ and titanium $(0.44 \mathrm{~mm}$ and $0.5 \mathrm{~mm})$ multistranded wire is also available (Dentaurum, Ispringen, Germany).

\section{Advantages and disadvantages}

Bonded retainers require less patient compliance, improved aesthetics and
Numerous wire diameters and materials 


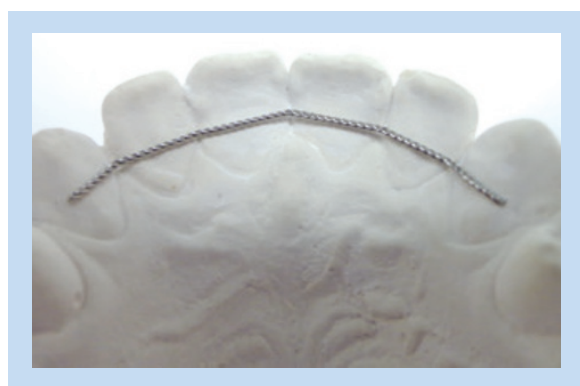

Fig. 4 A 0.0195" stainless steel three stranded wire retainer for the upper anterior teeth

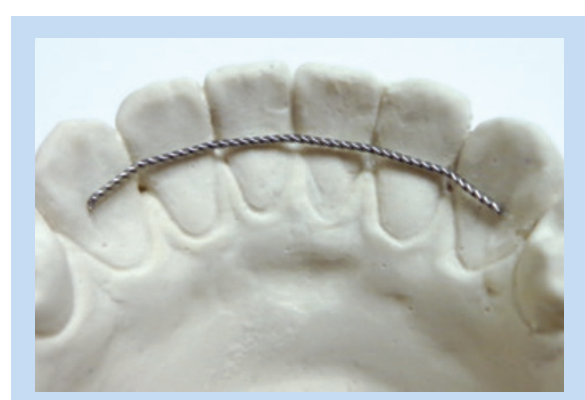

Fig. 5 A $0.0195^{\prime \prime}$ stainless steel three stranded wire retainer for the lower anterior teeth

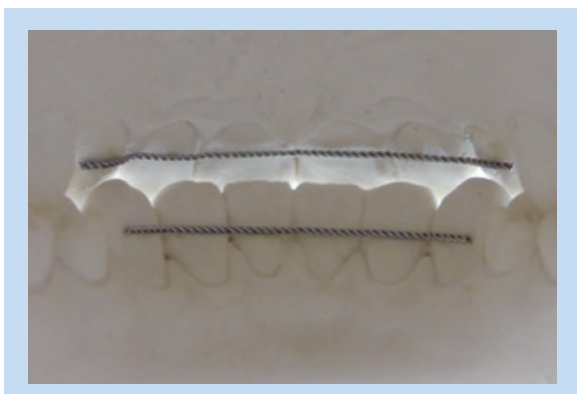

Fig. 6 Upper and lower retainers on models to ensure the wire does not impede the occlusion

be taken to ensure that the wire or composite does not obstruct the occlusion and torque may be introduced if the wire is not entirely passive, which can result in unwanted tooth movement. $^{28}$

The advantages and disadvantages of bonded retainers are summarised in Table 1.

\section{Fabrication}

The retainer will typically consist of a length of stainless steel multi-stranded wire bonded to the mid third of the palatal or lingual surfaces of each tooth in the anterior segment (Fig. 4 and 5) with composite. They can involve fewer teeth or may be extended around the second premolar to prevent space reopening in extraction cases. ${ }^{15}$ The retainer extends two thirds of the width of the last tooth involved to allow for composite encapsulation of the wire ends. The retainer may be fabricated directly on the teeth at the chairside or on a model. If constructing on a model, upper and lower impressions and a bite registration are necessary, even in cases where only an upper or lower retainer is required to confirm that the wire does not interfere with the occlusion (Fig. 6).

\section{Fitting}

Bonded retainer positioning can be assisted with dental floss, elastic separators ${ }^{29}$ or ligature wires. The use of an acrylic transfer tray, ${ }^{30,31}$ molar bands, ${ }^{32}$ ceramic locking elements ${ }^{33}$ and magnets ${ }^{34,35}$ have also been reported. Using a transfer stent has been found to be statistically significantly quicker than direct bonding. ${ }^{36}$

The enamel surface is cleaned and may be sandblasted to ensure that there is no moisture contamination prior to bonding. Light-cured composites are the favoured material for bonding the retainer. ${ }^{37} \mathrm{~A} 1 \mathrm{~mm}$ thickness of composite is used, any more can result in plaque retention and gingival inflammation. ${ }^{38}$ Glass ionomer cements are another option and these will bond to wet enamel surfaces and release fluoride to reduce the decalcification risk. Glass ionomers have a lower bond strength than composites but this should be sufficient for bonded retainers. ${ }^{39,40}$

\section{Long term maintenance}

While a bonded retainer may offer a 'permanent' retention solution, long term monitoring is required, as with any other appliance. Failure rates have been the focus of many studies ${ }^{13,27,41-46}$ and vary between $11 \%{ }^{13}$ and $50 \% .{ }^{27}$ Failures are more commonly seen during the first six months after bonding. . $^{434}$ Early failure is likely to be due to insufficient saliva isolation during bonding or insufficient composite. Failure after this period will probably be due to composite abrasion, occlusal forces or wire fatigue..$^{43,47}$

A thicker wire is likely to have a higher detachment rate because of increased rigidity ${ }^{47,48}$ but thinner wires can be distorted and will fracture more easily. ${ }^{21}$ Bonded retainers in the upper arch tend to have a higher failure rate than the lower arch, especially if extended to the canines ${ }^{21,43}$ - this may be because upper fixed retainers are exposed to greater occlusal forces.

Bonded retainers can fail due to a stress fracture of the wire or debond at the adhesiveenamel or wire-composite interface. ${ }^{26}$ The wire-composite interface has been reported as the most frequent site of failure, usually because of composite abrasion. ${ }^{37}$ This bond can be improved by sandblasting the wire ends prior to bonding. Sandblasting the enamel and avoiding wire movement during bonding should avoid bond failure at the adhesiveenamel interface. ${ }^{26}$

\section{Conclusion}

While no retention system is without its drawbacks, fixed retainers offer a significant benefit in that they need little patient compliance beyond keeping them clean. They are usually bonded to the palatal or lingual surfaces of the teeth, so are generally considered more aesthetic than removable retainers. The multi-stranded wire retainer has been found to deliver an effective method of providing long term retention because its flexibility permits physiological tooth movement and its greater surface area should give better mechanical retention for the composite.

\section{REFERENCES}

1. Sadowsky C. Long term assessment of orthodontic relapse. Am J Orthod 1982; 82: 456-463.

2. Sadowsky C, Schneider BJ, BeGole E, Tahir BS. Long-term stability after orthodontic treatment: nonextraction with prolonged retention. Am J Orthod Dentofacial Orthop 1994; 106: 243-249.

3. Melrose C, Millett DT. Toward a perspective on orthodontic retention? Am J Orthod Dentofacial Orthop 1998; 113(5) 507-514.

4. Mills JRE. The long term results of proclination of lower incisors. $\mathrm{Br}$ Dent $\mathrm{J}$ 1966; 120(8): 355-363.

5. Haas A. Long term post-treatment evaluation of rapid palatal expansion. Angle Orthod 1980; 50(3): 189-217.

6. Shields TE, Little RM, Chapko MK. Stability and relapse of mandibular anterior alignment: a cephalometric appraisal of first premolar extraction cases treated by traditional edgewise orthodontics. Am J Orthod 1985; 87(1): 27-38.

7. Årtun J, Krogstad O, Little RM. Stability of mandibular incisors following excessive proclination: a study in adults with surgically treated mandibular prognathism. Angle Orthod 1990; 60(2): 99-106.

8. McReynolds D, Little R. Mandibular second premolar extractions: postretention evaluation of stability and relapse. Angle Orthod 1991; 61(2): 133-144.

9. Reitan K. Clinical and histologic observations on tooth movement during and after orthodontic treatment. Am J Orthod 1967; 53(10): 721-745.

10. Clark JD, Kerr WJ, Davis MH. CASES clinical audit; scenarios for evaluation and study. Br Dent J 1997; 183(3): 108-111.

11. Nanda RS, Nanda SK. Considerations of dentofacial growth in long-term retention and stability: is active retention needed? Am J Orthod Dentofacial Orthop 1992; 101(4): 297-302. 
12. Littlewood S, Millett D, Doubleday B, Bearn $\mathrm{D}$, Worthington $\mathrm{H}$. Orthodontic retention: a systematic review. J Orthod 2006; 33(3): 205-212.

13. Bearn DR. Bonded orthodontic retainers: A review. Am J Orthod Dentofacial Orthop 1995; 108(2): 207-213.

14. Al Yami EA, Kuijpers-Jagtman AM, van ' $t$ Hof MA. Stability of orthodontic treatment outcome: follow-up until 10 years postretention. Am J Orthod Dentofacial Orthop 1999; 115(3): 300-304.

15. Kneirim RW. Invisible lower cuspid to cuspid retainer. Angle Orthod 1973; 43(2): 218-219.
25. Rody WJ Jr, Akhlaghi H, Akyalcin S, Wiltshire WA, Wijegunasinghe M, Filho GN. Impact of orthodontic retainers on periodontal health status assessed by biomarkers in gingival crevicular fluid. Angle Orthod 2011; 81: 1083-1089.

26. Årtun J, Spadagora AT, Shapiro PA. A 3-year follow-up study of various types of orthodontic canine-to-canine retainers. Eur J Orthod 1997; 19(5): 501-509.

27. Booth F, Edelman J, Proffit W. Twenty-year follow-up of patients with permanently bonded mandibular canine-to-canine retainers. Am J Orthod Dentofacial Orthop 2008; 133(1): 70-76.

\section{'EARLY FAILURE IS LIKELY TO BE DUE TO}

INSUFFICIENT SALIVA ISOLATION DURING
FAILURE AFTER THIS PERIOD WILL

\section{PROBABLY BE DUE TO COMPOSITE ABRASION.}

OCCLUSAL FORCES OR WIRE FATIGUE.

16.Zachrisson BU. Clinical experience with direct-bonded orthodontic retainers. Am J Orthod 1977; 71(4): 440-448.

17.Zachrisson BU. The bonded lingual retainer and multiple spacing of anterior teeth. Swed Dent J Suppl 1982; 15: 247-255.

18.Zachrisson BU. The bonded lingual retainer and multiple spacing of anterior teeth. J Clin Orthod 1983; 17(12): 838-844.

19. Haydar B, Haydar S. An indirect method for bonding lingual retainers. J Clin Orthod 2001; 35(10): 608-610.

20. Lim SM, Hong RK, Park JY. A new indirect bonding technique for lingual retainers. $J$ Clin Orthod 2004; 38(12): 652-655.

21.Zachrisson BU. Long term experience with direct-bonded retainers: update and clinical advice. J Clin Orthod 2007; 41(12): 728737.

22. Årtun J. Caries and periodontal reactions associated with long-term use of different types of bonded lingual retainers. Am J Orthod 1984; 86(2): 112-118.

23. Lew K. Direct-bonded lingual retainer. J Clin Orthod 1989; 23(7): 490-491.

24. Levin L, Samorodnitzky-Naveh GR, Machtei EE. The association of orthodontic treatment and fixed retainers with gingival health. J Periodontol 2008; 79(11): 20872092.
28. Katsaros C, Livas C, Renkema AM. Unexpected complications of bonded mandibular lingual retainers. Am J Orthod Dentofacial Orthop 2007; 132(6): 838-841.

29. Shah AA, Sandler PJ, Murray AM. How to ... place a lower bonded retainer. J Orthod 2005; 32(3): 206-210.

30.Zekic E, Gelgor IE. An acrylic transfer tray for direct bonded lingual retainers. J Clin Orthod 2004; 38(10): 551-553.

31. Costa MT, Lenza MA, Amorim-Brito RS. Bonding a $\mathrm{V}$ loop lingual retainer with a DuraLay transfer tray. J Clin Orthod 2005; 39(1): 44-46.

32. Upadhyay M, Yadav S, Keluskar KM. Molar bands for 'precision' bonding of lingual retainers. J Orthod 2007; 34(1): 12-15.

33. Amundsen OC, Wisth PJ. Clinical pearl: LingLock - the flossable fixed retainer. $J$ Orthod 2005; 32(4): 241-243.

34. Hahn W, Fricke J, Fricke-Zech S, Zapf A, Gruber R, Sadat-Khonsari R. The use of a neodymium - iron - boron magnet device for positioning a multi-stranded wire retainer in lingual retention - a pilot study in humans. Eur J Orthod 2008; 30(5): 433-436.

35. Yadav S, Upadhyay M, Patil S, Keluskar KM. Use of rare-earth magnets for bonding lingual retainers. J Clin Orthod 2008; 42(6): 349-350.
36. Bovali E, Kiliaridis S, Cornelis MA. Indirect vs direct bonding of mandibular fixed retainers in orthodontic patients: a single-center randomized controlled trial comparing placement time and failure over a 6-month period. Am J Orthod Dentofacial Orthop 2014; 146(6): 701-708.

37. Bearn D, McCabe J, Gordon P, Aird J. Bonded orthodontic retainers: The wire-composite interface. Am J Orthod Dentofacial Orthop 1997; 111(1): 67-74.

38. Geserick M, Ball J, Andrea W. Bonding fiber-reinforced lingual retainers with color-reactivating flowable composite. J Clin Orthod 2004; 38(10): 560-562.

39. Forss H, Seppa L, Lappalainen R. In vitro abrasion resistance and hardness of glass ionomer cements. Dent Mater 1991; 7(1) 36-39.

40. Baysal A, Uysal T. Resin-modified glass ionomer cements for bonding orthodontic retainers. Eur J Orthod 2010; 32(3):254258.

41.Dahl EH, Zachrisson BU. Long-term experience with direct-bonded lingual retainers. J Clin Orthod 1991; 25(10): 619630.

42.Lumsden KW, Saidler G, McColl JH. Breakage incidence with direct-bonded lingual retainers. Br J Orthod 1999; 26(3): 191-194.

43. Segner D, Heinrici B. Bonded Retainers Clinical Reliability. J Orofac Orthop 2000; 61: 352-358.

44.Lie Sam Foek DJ, Ozcan M, Verkerke GJ, Sandham A, Dijkstra PU. Survival of flexible, braided, bonded, stainless steel lingual retainers: a historic cohort study. Eur J Orthod 2008; 30(2): 199-204.

45. Renkema AM, Renkema A, Bronkhorst E, Katsaros C. Long-term effectiveness of canine-to-canine bonded flexible spiral wire lingual retainers. Am J Orthod Dentofacial Orthop 2011; 139(5): 614-621.

46. Pandis N, Fleming PS, Kloukos D, Poluchronopoulou A, Katsaros C, Eliades T. Survival of bonded lingual retainers with chemical or photo polymerization over a 2-year period: a single-center, randomized controlled clinical trial. Am J Orthod Dentofacial Orthop 2013; 144(2): 169-175.

47. Störmann I, Ehmer U. A prospective randomized study of different retainer types. J Orofac Orthop 2002; 63(1): 42-50.

48.Zachrisson BU. Third-generation mandibular bonded lingual 3-3 retainer. $J$ Clin Orthod 1995; 29(1): 39-48.

bdjteam201554 